\title{
Localization of the small monomeric GTPases Rab3D and Rab3A in the AtT- 20 rat pituitary cell line
}

\author{
G. Tabellini', G. Baldini', G. Baldini², R. Bortul', R. Bareggi', P. Narducci', and A.M. Martelli1,3,4
}

'Dipartimento di Morfologia Umana Normale, Università degli Studi di Trieste, Italy; ${ }^{2}$ Department of Anatomy and Cell Biology, Columbia University, College of Physicians and Surgeons, New York, USA; ${ }^{3}$ Dipartimento di Scienze Anatomiche Umane e Fisiopatologia dell'Apparato Locomotore, Sezione di Anatomia, Facoltà di Farmacia, Università degli Studi di Bologna, Italy; 'Istituto di Citomorfologia Normale e Patologica del CNR, c/o IOR, Bologna, Italy

Accepted: 1/10/01

Key words: Rab3D; Rab3A; AtT-20 cells; dense core granules; exocytosis; Golgi apparatus; endosomal compartment

\section{SUMMARY}

We investigated the cellular localization of the small GTPases Rab3D and Rab3A in AtT-20 cells treated with the drug Brefeldin A. Brefeldin A induces the redistribution of the Golgi complex into the endoplasmic reticulum and tubulation of endosomes. However, in Brefeldin A-treated wild-type AtT-20 cells, both Rab3D and Rab3A retained their distribution, indicating that they belong to a nonendosomal, post-Golgi compartment. Immunoelectron microscopy experiments indicated that both Rab3D and Rab3A localized to the ACTH-containing, large dense core granules. In contrast, in cell clones overexpressing a mutated form of Rab3D (Rab3D N135I), Rab3A did not localize to the dense core granules. Moreover, since our previous results showed that overexpression of Rab3D N135I severely impaired regulated ACTH secretion in AtT20 cells, we sought to determine whether the impairment could depend on a redistribution of two key components of the regulated exocytosis machinery, synaptotagmin and SNAP-25. As far as synaptotagmin was concerned, in cell clones overexpressing Rab3D N135I, the protein did not localize close to the plasma membrane, in agreement with the previously reported defective docking of dense core granules to the plasma membrane. Immunofluorescence experiments showed that SNAP-25 did not change its localization in these cell clones. All in all, our findings strengthen the notion that both Rab3D and Rab3A are associated with the dense core granule compartment of AtT-20 cells, and that the impairment in the ACTH secretion caused by overexpression of a mutated Rab3D form is likely to be due to a lacking of granule docking to the plasma membrane, possibly because Rab3A fails to associate with the granules.

\section{INTRODUCTION}

Rab proteins are low molecular weight GTP-ases belonging to the Ras superfamily that are thought to play a key role in the regulation of vesicle trafficking along exocytotic and endocytotic pathways in eukaryotes, where they regulate multiple, distinct steps of intracellular transport (Martinez and Goud, 1998; Chavrier and Goud, 1999; Armstrong, 2000). At present, almost $40 \mathrm{Rab}$ proteins have been identified and found to be associated with specific subcellular compartments (Martinez and Goud, 1998; Masuda et al., 2000; Yoshie et al., 2000).

Among Rab proteins, the four members of the Rab3 subfamily (Rab3A, Rab3B, Rab3C, Rab3D) 
have been found to be selectively expressed in regulated secretion-competent cells, and to be associated with synaptic vesicles or secretory granules, suggesting that they are involved in stimulus-secretion coupling (see Ybe et al., 2000; Moyer and Balch, 2001; Zerial and McBride, 2001 for updated reviews on this issue). Rab3A and -C are primarily expressed in neuronal and neuroendocrine cells, while Rab3B and -D are more abundant outside the nervous system (Baldini et al., 1992; Fischer von Mollard et al., 1994; Novick and Zerial, 1997; Al-Matubsi et al., 1999).

We have recently reported that in wild-type AtT-20 rat pituitary cells, Rab3D localizes to ACTH-containing dense core granules and that in a cell clone overexpressing a mutated Rab3D protein (Rab3D N135I) there is a marked impairment of regulated secretion of ACTH (Baldini et al., 1998). However, our immunofluorescence analysis results also showed a diffuse distribution of Rab3D immunoreactivity (Martelli et al., 1995; Baldini et al., 1998). Therefore, we reasoned that Rab3D, other than in dense core granules, may also be present in other cellular districts. Since Rab family members such as Rab33B, Rab6, Rab 4, Rab 5, Rab11 have been reported to be associated with either the Golgi apparatus or the endosomal compartment, respectively (Zheng et al., 1998; Trischler et al., 1999), we investigated by means of the drug Brefeldin A whether or not also Rab3D and/or Rab3A could be present in these domains of AtT-20 cells. It is well established that Brefeldin A induces a redistribution of the Golgi proteins into the endoplasmic reticulum (Lippincott-Schwarz et al., 1989) and fusion of the endosomal compartment and the Trans-Golgi Network into tubular structures (Lippincott-Schwarz et al., 1991). To label the Golgi apparatus we employed an antibody to the 58-kDa Golgi protein. Such a protein binds the Golgi apparatus to microtubules and redistributes to the endosplamic reticulum after treatment with Brefeldin A (Bloom and Brashear, 1989; Ktistakis et al., 1991).

Moreover, as a step towards the comprehension of the mechanisms through which Rab3D controls regulated ACTH secretion, we have studied the effect of overexpressing the mutated Rab3D N135I on the distribution of two proteins which are considered to be critical for regulated exocytosis, such as synaptotagmin, which has been reported to be associated with dense core granules (Walch-Solimena et al., 1993; Papini et al., 1995) and SNAP-25, a component of the t-SNARE complex (Sadoul et al.,1995).

\section{MATERIALS AND METHODS}

\section{Cell culture}

AtT-20 cells (both wild-type or overexpressing mutated Rab3D) were cultured in DME supplemented with $10 \%$ fetal calf serum. To label the endosomal compartment, the procedure described by Mundigl et al. (1993) was followed. Briefly, cells grown on poly-L-lysine-coated coverslips for at least $24 \mathrm{~h}$, were incubated for $1 \mathrm{~h}$ at $37^{\circ} \mathrm{C}$ in the presence of $2.5 \mu \mathrm{g} / \mathrm{ml}$ of Texas red-conjugated human transferrin (Molecular Probes, Eugene, OR). Samples were then incubated for an additional 40 $\min$ at $37^{\circ} \mathrm{C}$ in the presence of the fungal metabolite, Brefeldin A (10 $\mu \mathrm{g} / \mathrm{ml}$, Sigma Chemical Co, St. Louis, MO). Addition of an equivalent amount of solvent (ethanol) was without effect.

The AtT-20 cell clones overexpressing mutated Rab3D N135I (clones A3C1 and A3C4) were as previously reported. This mutation impairs the GTP binding capability of Rab3D (Baldini et al., 1998).

\section{Immunofluorescent staining}

For immunofluorescent staining, AtT-20 cells, grown on coverslips, were briefly washed with phosphate buffered saline (PBS), then fixed for 20 min at room temperature in $4 \%$ freshly-prepared paraformaldehyde in PBS. Samples were permeabilized with $0.2 \%$ Triton X-100 in PBS for $10 \mathrm{~min}$ at room temperature and washed three times in PBS. They were then incubated with the following primary antibodies, all diluted in PBS containing $3 \%$ bovine serum albumin (BSA) and $2 \%$ normal goat serum (NGS): monoclonal antibody to Golgi 58-kDa protein (1:50, Sigma); affinity-purified rabbit antibody to Rab3D (1:200, see Martelli et al., 1995); monoclonal antibody to SNAP-25 (1:1000, Sternberg Monoclonals Inc., Baltimore, MD); monoclonal antibody to synaptotagmin (1:100, clone SY130, Stressgen Biotechnologies Corp., Victoria, B.C., Canada); monoclonal antibody to Rab3A (Matteoli et al., 1991) (used 1:100, a kind gift from Dr. R. Jahn).

After several washes in PBS, samples were reacted with the appropriate secondary antibodies (diluted 1:200 in PBS, 3\% BSA, 2\% NGS), i.e. $\mathrm{Cy}-3$-conjugated anti-mouse $\mathrm{IgG}$ or fluorescein isothyocyanate-conjugated anti-rabbit IgG (both from Sigma).

Slides were observed and photographed using a Zeiss Axiophot epifluorescence microscope. 


\section{Immunoelectron microscopy}

Immunogold labelling of agarose embedded AtT20 cells was performed as reported, using the broken cell method (Baldini et al., 1998). Briefly, preconfluent cells were scraped in ice-cold homogenization buffer containing $250 \mathrm{mM}$ sucrose, $25 \mathrm{mM} \mathrm{KCl,} 2$ mM EGTA, and $10 \mathrm{mM}$ sodium phosphate, $\mathrm{pH} 6.5$. Cells were lightly homogenized by a passage through a 20 -gauge needle fitted to a 5-ml syringe. Cells were fixed by addition of 15 vol of ice-cold fixative solution containing $300 \mathrm{mM}$ sucrose, $3 \%$ freshly prepared paraformaldehyde, $0.25 \%$ glutaraldehyde, and $5 \mathrm{mM}$ sodium phosphate, $\mathrm{pH}$ 6.5. Cells were kept in the fixative solution for $30 \mathrm{~min}$, pelleted by centrifugation at $1,000 \mathrm{~g}$ for $10 \mathrm{~min}$, and then resuspended in $4 \mathrm{vol}$ of $120 \mathrm{mM}$ sodium phosphate, $\mathrm{pH}$ 7.5. The entire procedure was carried out at $4^{\circ} \mathrm{C}$. Broken cells were agarose-embedded as described elsewhere (De Camilli et al., 1983). Incubations of agarose-embedded samples with either polyclonal antibody to Rab3D (1:20) or monoclonal antibody to Rab3A (1:25) was done as described (Jena et al., 1994). For gold immunolabeling, $10 \mathrm{~nm}$ colloidal gold-conjugated anti-rabbit IgG were used to detect Rab3D, while for Rab3A detection $5 \mathrm{~nm}$ colloidal gold-conjugated anti-mouse $\mathrm{IgG}$ were used (both diluted 1:25, from Biocell International, Cardiff, UK).

\section{RESULTS}

To better define the localization of both Rab3D and Rab3A in AtT-20 cells, we used the fungal metabolite, Brefeldin A. Antibody to 58-kDa protein labeled the Golgi complex in control AtT-20 cells (Fig. 1A). After addition of $10 \mu \mathrm{g} / \mathrm{ml}$ Brefeldin A for $40 \mathrm{~min}$ at $37^{\circ} \mathrm{C}$, the $58-\mathrm{kDa}$ polypeptide immunofluorescent staining changed into a finer and more diffuse pattern, indicating that a disruption of the Golgi apparatus occurred (Fig. 1B). We next analyzed the effects of Brefeldin A on the morphology of the endosomal compartment and on Rab3D distribution by double immunofluorescence experiments. In wild-type AtT20 cells, Rab3D displayed its characteristic diffuse distribution (Fig. 1C). AtT-20 cells were incubated with iron-bound, Texas Red-conjugated transferrin for $1 \mathrm{~h}$ at $37^{\circ} \mathrm{C}$, to label the endosomal compartment. Transferrin was distributed over the entire cellular body decorating the plasma membrane and accumulated at the perinuclear region (Fig. 1D). Cells were first incubated with Texas Red-conjugated transfer- rin and then incubated for $40 \mathrm{~min}$ at $37^{\circ} \mathrm{C}$ in the presence of Brefeldin A and immunostained for Rab3D. The drug induced a segregation of the transferrin fluorescence in a perinuclear region from which some long tubular structures extended to the cell periphery (Fig. 1E). Compare the transferrin distribution without (Fig. 1D) and with (Fig. 1F) incubation with Brefeldin A. Instead, the punctate fluorescent distribution of Rab3D was unchanged (compare Fig. 1E, Rab3D with Brefeldin A incubation; with Fig. 1C untreated AtT-20 cells immunostained for Rab3D) and the Rab3D-labeled compartment did not form tubules. After addition of Brefeldin A, also Rab3A did not change its punctate fluorescent distribution at the cell body and its characteristic accumulation at the tips of the processes (compare Fig. 1G and Fig. 1H).

We next examined, by immunofluorescent staining, the cellular distribution of Rab3D in wild-type AtT-20 cells as compared with clones overexpressing mutated Rab3D. In wild-type cells, Rab3D displayed the characteristic diffuse and punctate fluorescence (Martelli et al., 1995; Baldini et al., 1998) which was also present in the tips of the processes (Fig. 2A and B), whereas, in both $\mathrm{A} 3 \mathrm{C} 1$ and $\mathrm{A} 3 \mathrm{C} 4$ cell clones, the immunostaining was more homogeneously distributed, less punctated, and absent from the tips (Fig. 2, panels C, D, and E). A merging of the phase contrast and of immunofluorescent staining confirmed that the tips of clone $\mathrm{A} 3 \mathrm{C} 4$ were indeed devoid of staining (Fig. 2, panel G).

We next performed immunoelectron microscopy on agarose-embedded, broken AtT-20 cells (both wild-type and overexpressing Rab3D N135I), double-labeled for Rab3D and Rab3A. As shown in Fig. 3 (panel A) both Rab3D and Rab3A were localized to dense core granules present at the tips of wild-type AtT-20 cells. Interestingly, in cells overexpressing mutated Rab3D (clone A3C1), the amount of Rab3D bound to dense core granules was reduced and no Rab3A was found on these organelles (Fig. 3, panel B). Similar results were obtained with the A3C4 clone (data not shown).

To further strengthen this conclusion, we immunostained for Rab3A both wild type AtT-20 cells and clones $\mathrm{A} 3 \mathrm{C} 1$ and $\mathrm{A} 3 \mathrm{C} 4$. As presented in Fig. 4 (panel A), in wild-type AtT-20 cells Rab3A was located both in the cell body and at the tips. In contrast, in both clone $\mathrm{A} 3 \mathrm{C} 1$ (panel B) and A3C4 (panel C), the tips were devoid of immunoreactivity.

As far as synaptotagmin distribution was concerned, it should be stressed that in wild-type AtT- 

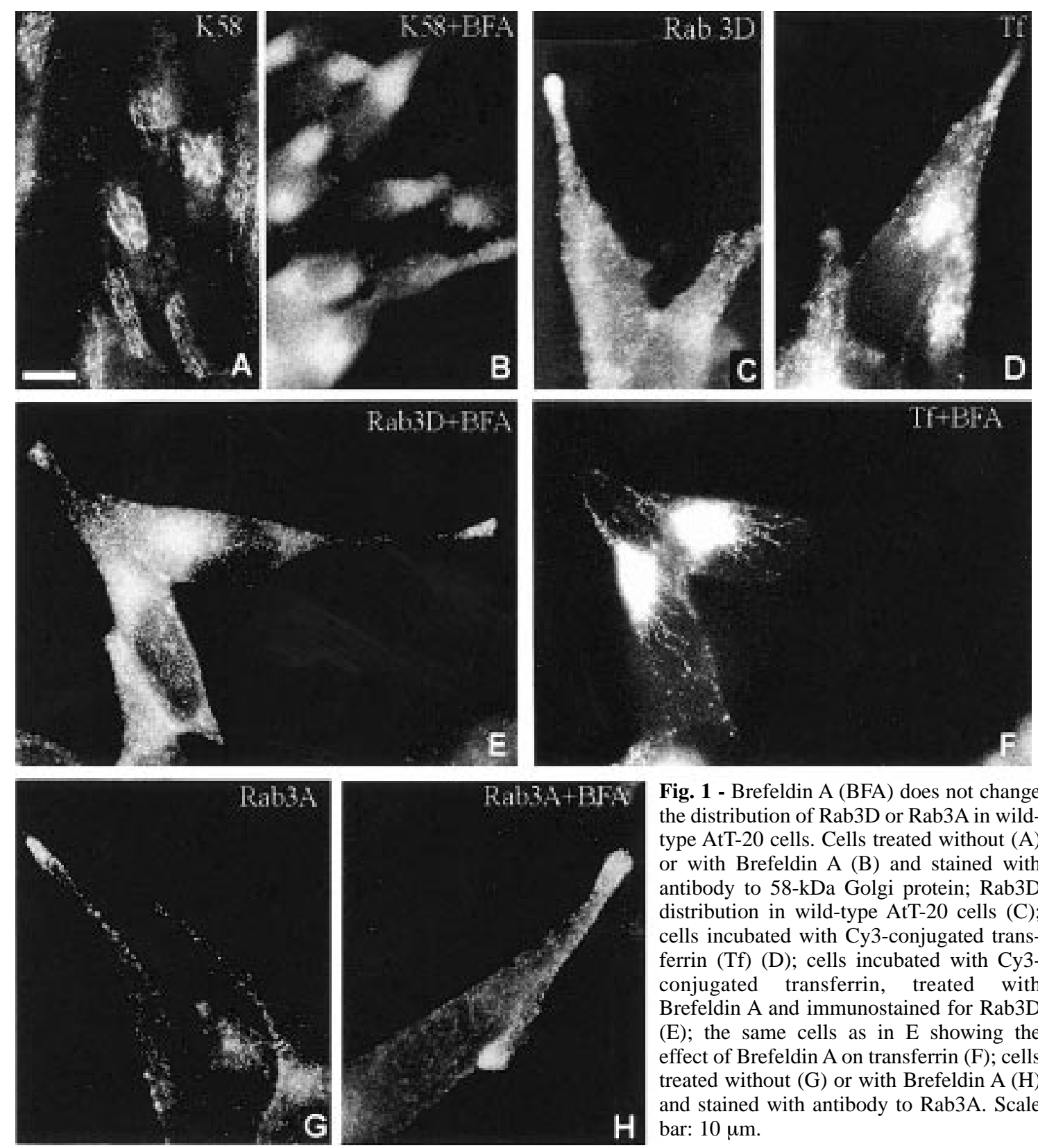
the distribution of Rab3D or Rab3A in wildtype AtT-20 cells. Cells treated without (A) or with Brefeldin A (B) and stained with antibody to 58-kDa Golgi protein; Rab3D distribution in wild-type AtT-20 cells (C); cells incubated with Cy3-conjugated transferrin (Tf) (D); cells incubated with $\mathrm{Cy} 3$ conjugated transferrin, treated with Brefeldin A and immunostained for Rab3D (E); the same cells as in E showing the effect of Brefeldin A on transferrin (F); cells treated without $(\mathrm{G})$ or with Brefeldin $\mathrm{A}(\mathrm{H})$ and stained with antibody to Rab3A. Scale

20 cells, the immunoreactivity, besides a diffuse distribution, showed in some cases an accumulation near the plasma membrane, with an aspect reminiscent of beads-on-a string (Fig. 5A). In A3C1 cells, we never saw such an accumulation, consistent with the impaired docking of dense core granules to the plasma membrane (Fig. 5B). Similar results were obtained with the $\mathrm{A} 3 \mathrm{C} 4$ clone (Fig. 5C).

When $\mathrm{A} 3 \mathrm{C} 1$ cells were immunostained for SNAP25 , we found that the immunoreactivity accumulated at the cell periphery similarly to wild-type AtT-20 cells
(Fig. 5, compare E with D). Therefore, overexpression of Rab3D N135I did not prevent targeting of a tSNARE component to the plasma membrane. Similar data were obtained with the A3C4 clone (Fig. 5F).

\section{DISCUSSION}

A key step in the understanding of the functions played by Rab proteins is to define the subcellular 

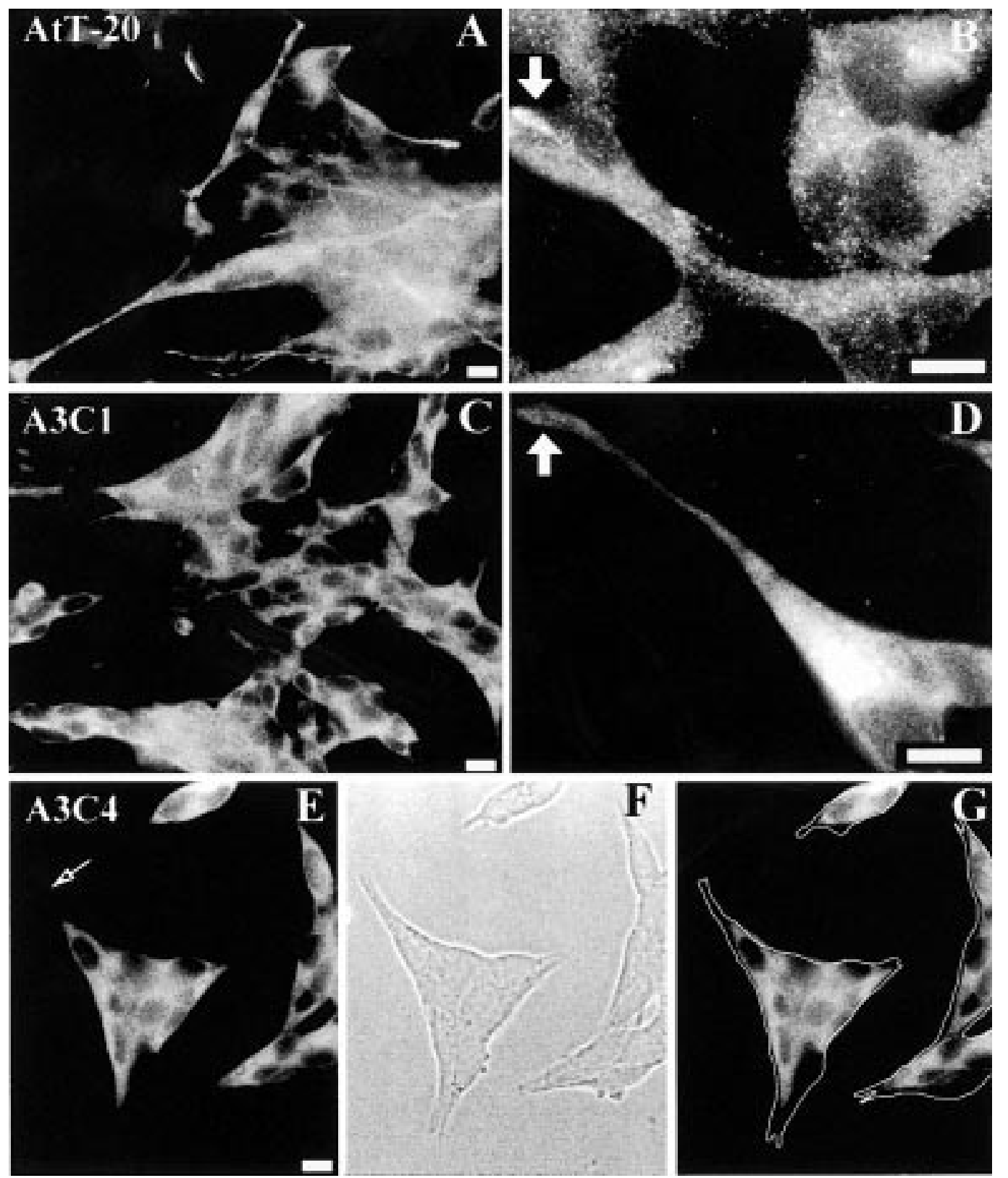

Fig. 2 - Comparison of Rab3D distribution between wild-type AtT-20 cells (A, B) and cell clones overexpressing Rab3D N135I: $\mathrm{A} 3 \mathrm{C} 1(\mathrm{C}, \mathrm{D})$ and $\mathrm{A} 3 \mathrm{C} 4$ (E, F, G). The low magnification pictures (A, C, E) show that Rab3D immunostaining of cell clones is more homogeneously distributed and absent from the tips. Both $\mathrm{A} 3 \mathrm{C} 1$ and $\mathrm{A} 3 \mathrm{C} 4$ cells have tips but they are not stained and in the cell body the fluorescence is not as punctate (D) as in wild-type AtT-20 cells (B). Arrows indicate cell tips. Note that in wildtype AtT-20 cells (D) the tips are heavily immunostained by antibody to Rab3D, whereas in cell clones overexpressing mutated Rab3D tips are either barely stained (D) or completely unstained (E) . Panel $G$ shows a merging of panel $F$ with panel $E$ to emphasize the fact that there is no fluorescent staining at the tips. Scale bar: $10 \mu \mathrm{m}$.

domains to which these GTPases are associated. In the present investigation, we first employed the fungal toxin, Brefeldin A, to determine whether or not Rab3D and/or Rab3A localize to either the
Golgi apparatus or the early endosomal compartment. Indeed, Brefeldin A is known to induce major structural changes in cellular compartments involved in constitutive secretion and recycling, 

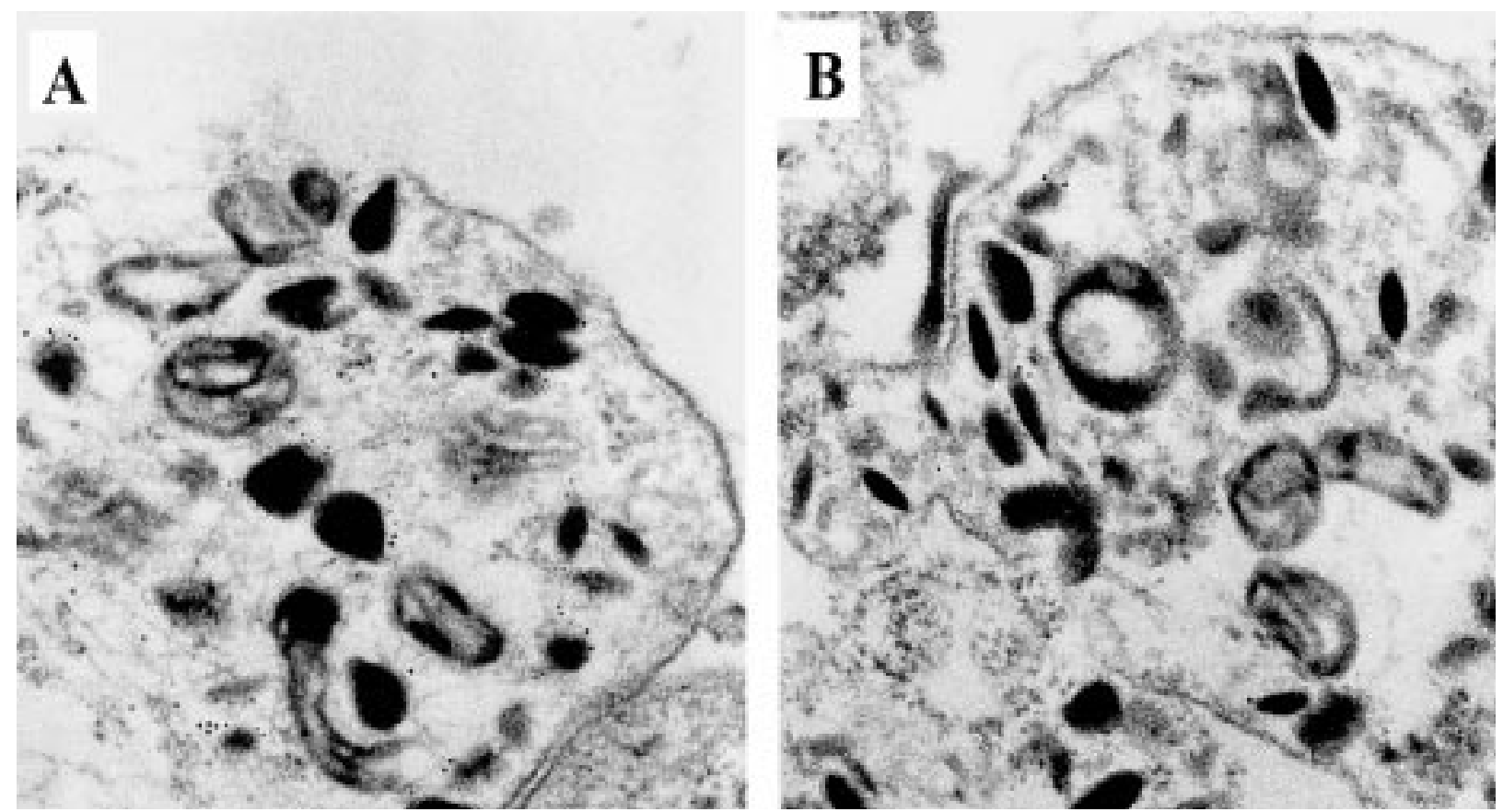

Fig. 3 - Ultrastructural analysis of Rab3D (10 nm gold) and Rab3A (5 nm gold) distribution in broken, wild-type AtT-20 (A) and A3C1 clone cells (B). In both of these pictures a portion of a cell tip in shown. Note that in wild-type cells both Rab3A and Rab3D immunoreactivity is associated with the granules with no labeling at the plasma membrane of the cell. In contrast, in $\mathrm{A} 3 \mathrm{C} 1$ cells there is lower immunoreactivity for Rab3D and Rab3A is not labeled at all. Scale bar: $100 \mathrm{~nm}$.

whereas the morphology of late regulated secretory organelles is preserved (Matteoli et al., 1991). However, our results indicated that in Brefeldin Atreated AtT-20 cells, both Rab3D and Rab3A retained their characteristic diffuse fluorescence, and did not form tubules. On the contrary, the fluorescent signal given by either Texas Red-conjugated transferrin or the $58-\mathrm{kDa}$ Golgi protein changed in a dramatic manner, indicating the efficacy of the Brefeldin A treatment. These results suggest that, in AtT-20 cells, both Rab3D and Rab3A are present in a post-Golgi, non-endosomal compartment. Thus, Rab3D conceivably associates only with the dense core granules of AtT-20 cells (Baldini et al., 1998), even though at present we do not know whether Rab3D is a component of the more mature granules, or is also present in granules that leave the Golgi and in secretory vesicles at an intermediate stage of maturation.

Our findings are in agreement with the data reported by Mundigl et al. (1993) who did not observe a redistribution of Rab3A in Brefeldin A-exposed cultured hippocampal neurons. However, others have recently demonstrated that Rab3A is associated with an endosomal compartment in bovine chromaffin cells in primary culture (Slembrouck et al., 1999). It is conceivable that these discrepancies are due to the different cell systems employed in these investigations. Alternatively, the existence of a Brefeldin A-insensitive endosomal compartment could not be ruled out, although at present such a compartment has not yet been identified (e.g. Blagoveshchenskaya and Cutler, 2000).

It is interesting that in AtT-20 cells, also Rab3A was found to be associated with dense core granules. It was originally thought that Rab3A was a component of synaptic vesicles (Sudhof and Jahn, 1991; Chou and Jahn, 2000). However, a number of more recent reports have indicated that Rab3A is also present in the dense core granules of various cell lines, including PC12 and insulin-secreting HIT-T15 or INS-1 cells (e.g. Darchen et al., 1995; Regazzi et al., 1996; Iezzi et al., 1999; Chung et al., 1999). Our previous results (Martelli et al., 1995; Baldini et al., 1998) have demonstrated that in wildtype AtT-20 cells, Rab3D and Rab3A did not for the most part co-localize, their immunofluorescent patterns being different. From the data presented in this paper we can infer that the two proteins co-localize at the dense core granules but not in other cell 

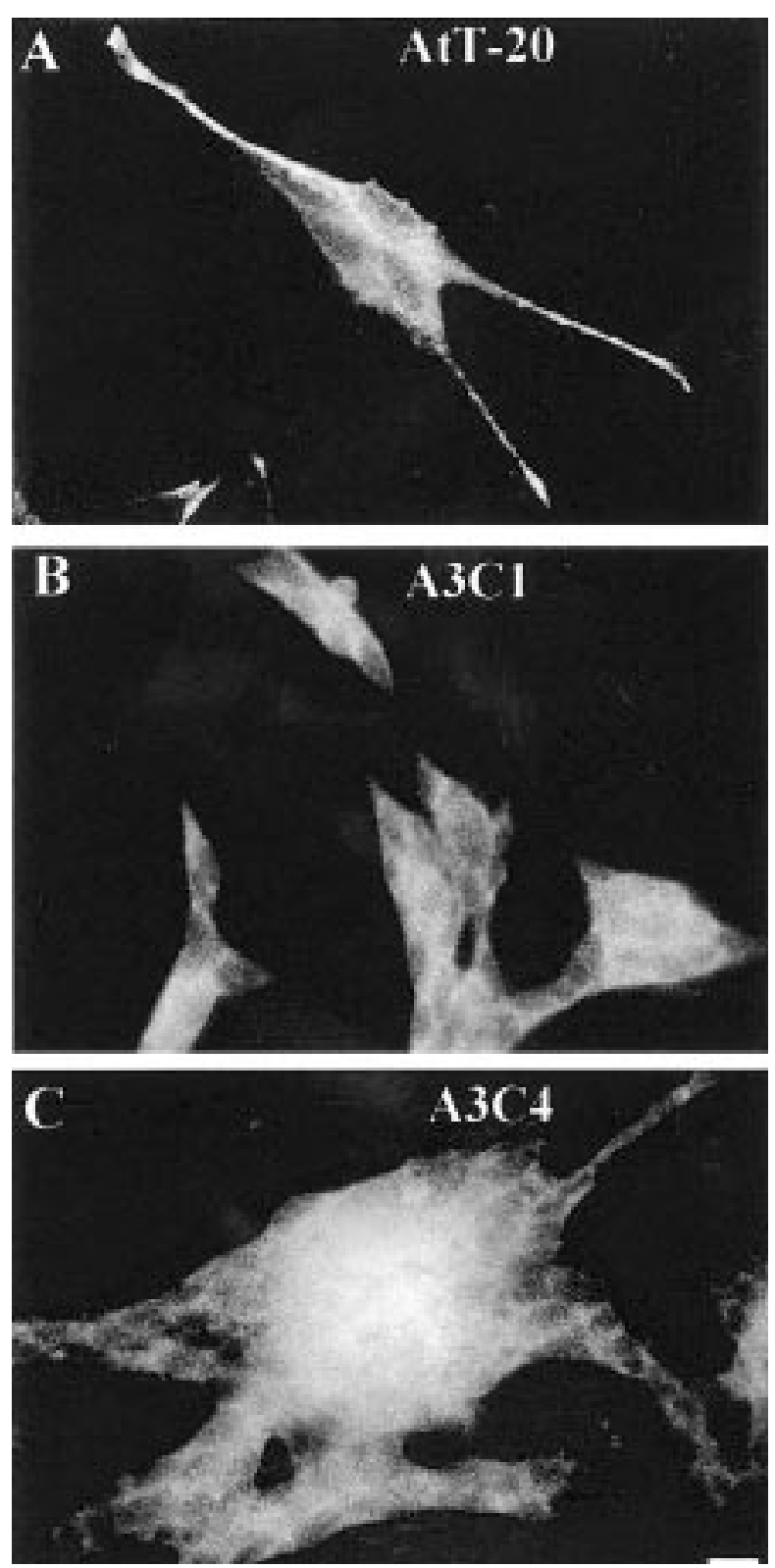

Fig. 4 - Immunofluorescence staining for Rab3A in wild-type AtT-20 cells and cells clones overexpressing mutated Rab3D. A: wild-type AtT-20 cells; B: clone A3C1; C: clone A3C4. Note the absence of Rab3A immunoreactivity at the tips of the processes in the two cell clones. Bar: $10 \mu \mathrm{m}$.

domains, even though their behavior in response to Brefeldin A was similar.

To further explore the mechanisms by which Rab3D controls regulated secretion in AtT-20 cells, we overexpressed a mutated form of Rab3D. In cell clones overexpressing this form, we observed a reduction in the Rab3D immunoreactivity present on dense core granules. Moreover, Rab3A was not found associated with the dense core granules. This may indicate that a sort of cross-talk exists between Rab3A and Rab3D, and that a functional Rab3D is necessary for a correct association of Rab3A with dense core granules. The absence of Rab3A from dense core granules of $\mathrm{A} 3 \mathrm{C} 1$ cells, as demonstrated by immunoelectron microscopy, is in agreement with our own previous findings obtained by Western blotting analysis that showed a relative inability of Rab3A to bind to organelles of A3C1 cells (Baldini et al., 1998). It should be pointed out that in the clones overexpressing mutated Rab3D, very low levels of Rab3D were seen by immunoelectron microscopy on dense core granules. In contrast, the same cells were positive by immunofluorescence. This may be another indication that in these clones most of the Rab3D (both the endogenous and the mutated form) is present in a soluble form and not associated with secretory granules, given that our antibody to Rab3D recognizes both the wild-type and the mutated form of the protein. Conceivably, the soluble form of Rab3D is lost when cells are "broken" for immunoelectron microscopy, whereas it is retained in cells fixed for immunofluorescent staining. At present, it is not clear how the mutated form of Rab3D could impair the association of wildtype Rab3D with the granules.

Fusion of dense core granules is thought to occur prevalently at the tips of AtT-20 cells, as dense core granules as well as synaptic-like microvesicles are accumulated there (Matsuuchi et al., 1988; Rivas and Moore, 1989; Ngsee et al., 1993). In wild-type AtT-20 cells, we have found that dense core granules are clustered very near the plasmalemma at the cell body indicating that the sites for docking/fusion of granules are distributed along the entire cell surface (Baldini et al., 1998). We reasoned that overexpression of mutated Rab3D N135I might disrupt these sites and impair the ability of the granules to dock to the plasma membrane. SNAP-25 is a tSNARE component thought to be involved in docking of hormone-containing granules (Sadoul et al., 1995). However, we did not find any significant differences in the distribution of SNAP-25 between wild-type AtT-20 cells and cell clones overexpressing a mutated Rab3D form. Therefore, it is tempting to speculate that the impairment of granule docking we observed in $\mathrm{A} 3 \mathrm{C} 1$ cells is dependent on the failure of Rab3A to associate with the membrane of large dense core granules. In agreement with a recent model proposed for neuro-exocytosis (Wang 

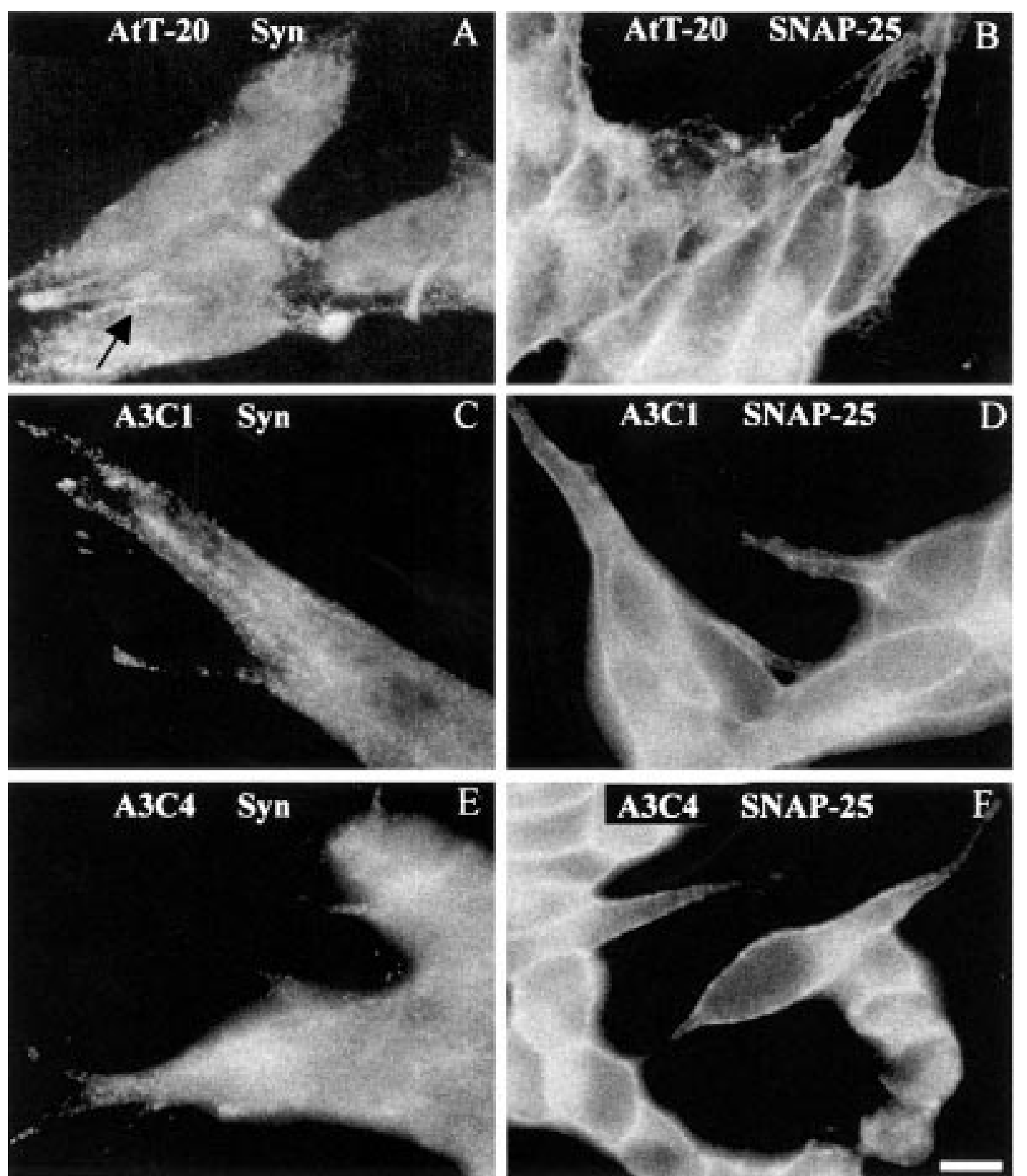

Fig. 5 - Distribution of synaptotagmin (Syn, A,C,E) and SNAP-25 (B,D,F) in wild-type AtT-20 cells and cell clones overexpressing a mutated Rab3D. Wild-type cells (A, B), A3C1 (C,D), and A3C4 (E,F) cells were immunostained with a monoclonal antibody to synaptotagmin. In A the arrow points to the characteristic "beads on a string" distribution of synaptotagmin. Scale bar: $10 \mu \mathrm{m}$.

et al., 1998), the dense core granules would be clamped by the interaction of Rab3A-GTP on their surface with the protein referred to as RIM (for RabInteracting Molecule), which is localized at the plasma membrane close to L-type $\mathrm{Ca}^{2+}$ channels (Iezzi et al., 2000). The absence of Rab3A from dense core granules would prevent the interaction with RIM, thus resulting in a failure of docking. Alternatively, it may be that in the absence of Rab3A, the dense core granules fail to interact with yet another putative effector of Rab3A, that is rabphilin-3A (Schluter et al., 1999). This protein has been reported to be a component of dense core granules of bovine chromaffin cells and is thought to be an 
enhancer of regulated exocytosis (Chung et al., 1995). However, it should be recalled that in AtT-20 cells, rabphilin-3A is expressed at very low levels (G. Tabellini, unpublished experiments). Therefore, other effectors of Rab3A, which are more abundant in endocrine cells such as the recently described granuphilin, could be involved (Wang et al., 1999).

It should be emphasized that we have recently reported that in PC-12 cells, overexpressed Rab3A N135I still associates with dense core granules but is capable of impairing docking (Martelli et al., 2000). Therefore, the results presented here likely do not reflect a universal phenomenon, even though others have shown that in PC-12 cells the overexpressed N135I mutated form of Rab3B failed to correctly bind to organelle membranes (Weber et al., 1996).

We have previously shown that the amount of synaptotagmin, Vamp2/synaptobrevin 2, and SNAP25 , are similar in wild-type AtT-20 cells and in cell clones overexpressing Rab3D N135I (Baldini et al., 1998). However, we did not rule out the possibility that these proteins, which are important for regulated secretion, changed their localization. The results presented in this manuscript clearly demonstrated that SNAP-25 did not change its location in clones overexpressing mutated Rab3D. Thus, the impairment in the ACTH secretion that we measured in AtT-20 cells overexpressing mutated Rab3D (Baldini et al., 1998) cannot be explained by changes in the expression and/or localization of this key component of the secretory machinery.

On the other hand, the fact the synaptotagmin immunofluorescent distribution was different in both $\mathrm{A} 3 \mathrm{C} 1$ and $\mathrm{A} 3 \mathrm{C} 4$ cell clones when compared to controls, is conceivably due to the fact that in these cells the dense core granules are not docked to the plasma membrane.

Taken together, we feel that these results will provide an important basis for further investigations aimed at a complete understanding of the mechanisms regulated by Rab3D and Rab3A that lead to granule docking at the plasma membrane.

\section{ACKNOWLEDGEMENTS}

We thank Dr. R. Jahn (Dept. of Neurobiology, Max Planck Institute for Biophysical Chemistry, Gottingen, Germany) for kindly giving the antibody to Rab3A. This work was supported by Italian MURST "Cofinan 1999" to Paola Narducci, and by a National Institutes of Health grant \#RO1-DK53293 to Giulia Baldini.

\section{REFERENCES}

Al-Matsubi H.Y., Breed W., Jenkin G., and Fairclough R.J.: Co-localization of Rab3B and oxytocin to electron dense granules of the sheep corpus luteum during the estrous cycle. Anat. Rec. 254, 214-221, 1999.

Armstrong J.: How do Rab proteins function in membrane traffic? Int. J. Biochem. Cell Biol. 32, 303-307, 2000.

Baldini G., Hohl T., Lin H.Y., and Lodish H.F.: Cloning of a Rab3 isotype predominantly expressed in adipocytes. Proc. Natl. Acad. Sci. USA. 89, 5049-5052, 1992.

Baldini G., Baldini G., Wang G., Weber M., Zweyer M., Bareggi R., Witkin J.W., and Martelli A.M.: Expression of Rab3D N135I inhibits regulated secretion of ACTH in AtT-20 cells. J. Cell Biol. 140, 305-313, 1998.

Blagoveshchenskaya A.D., and Cutler D.F.: Sorting of synaptic-like microvesicles from early and late endosomes requires overlapping but not identical targeting signals. Mol. Biol. Cell. 11, 1801-1814, 2000.

Bloom G.S, and Brashear T.A.: A novel 58-kDa protein associates with the Golgi apparatus and microtubules. J. Biol. Chem. 264, 16083-16092, 1989.

Chavrier P., and Goud B.: The role of ARF and Rab GTPases in membrane transport. Curr. Opin. Cell. Biol. 11, 466-475, 1999.

Chou J.H, and Jahn R.: Binding of Rab3A to synaptic vesicles. J. Biol. Chem. 275, 9433-9440, 2000.

Chung S.H., Joberty G., Gelino E.A., Macara I.G., and Holz R.W.: Comparison of the effects on secretion in chromaffin and PC12 cells of Rab3 family members and mutants. J. Biol. Chem. 274, 18113-18120, 1999.

Darchen F., Senyshyn J., Brondyk W.H., Raatjes D.J., Holz R.W., Henry J.P., Denizot J.P., and Macara I.G.: The GTPase Rab3a is associated with large dense core vesicles in bovine chromaffin cells and rat PC12 cells. J. Cell Sci. 108, 16391649, 1995.

Fischer von Mollard G., Stahl B., Li C., Sudhof T.C., and Jahn R.: Rab proteins in regulated exocytosis. Trends Biochem. Sci. 19, 164-168, 1994.

Ktistakis N.T., Roth M.G., and Bloom G.S.: PtK1 cells contain a nondiffusible, dominant factor that makes the Golgi apparatus resistant to Brefeldin A. J. Cell Biol. 113, 10091032, 1991.

Iezzi M., Escher G., Meda P., Charollais A., Baldini G., Darchen F., Wollheim C.B., and Regazzi R.: Subcellular distribution and function of Rab3A, B, C, and D isoforms in insulin-secreting cells. Mol. Endocrinol. 13, 202-212, 1999.

Lippincott-Schwartz J., Yuan L., Bonifacino J.S., and Klausner R.D.: Rapid redistribution of Golgi proteins into the ER in cells treated with Brefeldin A: evidence for membrane cycling from Golgi to ER. Cell 56, 801-813, 1989. 
Lippincott-Schwartz J., Yuan L., Tipper C., Amherdt M., Orci L., and Klausner R.D.: Brefeldin's A effects on endosomes, lysosomes, and the TGN suggest a general mechanism for regulating organelle structure and membrane traffic. Cell 67 601-616, 1991

Martelli A.M, Bareggi R., Baldini G., Scherer P.E., Lodish H.F., and Baldini G.: Diffuse vesicular distribution of Rab3D in the polarized neuroendocrine cell line AtT-20. FEBS Lett. $368,271-275,1995$

Martelli A.M., Baldini G., Tabellini G., Koticha D., Bareggi R., and Baldini G.: Rab3A and Rab3D control the total granule number and the fraction of granules docked at the plasma membrane in PC-12 cells. Traffic 1, 976-986, 2000.

Martinez O., and Goud B.: Rab proteins. Biochim. Biophys Acta 1404, 101-112, 1998

Masuda E.S., Luo Y., Young C., Shen M., Rossi A.B., Huang B.C.B., Yu S., Bennett M.K., Payan D.G., and Scheller R.H. Rab 37 is a novel mast cell specific GTPase localized to secretory granules. FEBS Lett. 470, 61-64, 2000

Matsuuchi L., Buckely K.M., Lowe A.W., and Kelly R.B. Targeting of secretory vesicles to cytoplasmic domains in AtT-20 and PC-12 cells. J. Cell Biol. 106, 239-251, 1988.

Matteoli M., Takei K., Cameron R., Hurlbut P., Johnston P.A., Sudhof T.C., Jahn R., and De Camilli P.: Association of Rab3A with synaptic vesicles at late stages of the secretory pathways. J. Cell Biol. 115, 625-633, 1991.

Moyer B.D., and Balch W.E.: Structural basis for Rab function: an overview. Methods Enzymol. 329, 3-6, 2001.

Mundigl O., Matteoli M., Daniell L., Thomas-Reetz A., Metcalf A., and Jahn R.: Synaptic vesicle proteins and early endosomes in cultured hippocampal neurons: differential effects of Brefeldin A in axon and dendrites. J. Cell Biol. 122, 1207-1221, 1993.

Ngsee J.K., Fleming A.M., and Scheller R.H.: A Rab protein regulates the localization of secretory granules in AtT-20 cells. Mol. Biol. Cell. 4, 747-56, 1993.

Novick P., and Zerial M.: The diversity of Rab proteins in vesicle transport. Curr. Opin. Cell. Biol. 9, 496-504, 1997.

Regazzi R., Ravazzola M., Iezzi M., Lang J., Zahraoui A., Andereggen E., Morel P., Takai Y., and Wollheim C.B. Expression, localization and functional role of small GTPases of the Rab3 family in insulin-secreting cells. J. Cell Sci. 109 , 2265-2273, 1996.

Rivas R.J., and Moore H.P.: Spatial segregation of the regulated and constitutive secretory pathways. J Cell. Biol. 109, 51-60, 1989.

Robertson A.M., and Allan V.J.: Brefeldin A-dependent membrane tubule formation reconstituted in vitro is driven by cell cycle-regulated microtubule motor. Mol. Biol. Cell 11 , 941-55, 2000.

Sadoul K., Lang J., Montecucco C., Weller U., Regazzi R., Catsicas S., Wollheim C.B., and Halban P.A.: SNAP-25 is expressed in islets of Langerhans and is involved in insulin release. J. Cell. Biol. 128, 1019-1028, 1995.
Schutler O.M., Schnell E., Verhage M., Tzonopoulos T., Nicoll R.A., Janz R., Malenka R.C., Geppert M., and Sudhof T.C.: Rabphilin knock-out mice reveal that rabphilin is not required for Rab3 function in regulating neurotransmitter release. J. Neurosci. 19, 5834-5846, 1999.

Slembrouck D., Annaert W.G., Wang J.M., and De Potter W.P.: Rab3 is present on endosomes from bovine chromaffin cells. J. Cell. Sci. 112, 641-649, 1999.

Sudhof T.C, and Jahn R.: Proteins of synaptic vesicles involved in exocytosis and membrane recycling. Neuron 6 , 665-677, 1991.

Trischler M., Soorvogel W., and Ullrich O.: Biochemical analysis of distinct Rab5- and Rab11-positive endosomes along the transferrin pathway. J. Cell Sci. 112, 4773-4783, 1999.

Walch-Solimena C., Takei T., Marek K.L., Midyett K., Sudhof T.C., De Camilli P., and Jahn R.: Synaptotagmin: a membrane constituent of neuropeptide-containing large densecore vesicles. J. Neurosci. 13, 3895-3903, 1993.

Wang Y., Okamoto M., Schmitz F., Hofmann K., and Sudhof T.C.: Rim is a putative Rab3 effector in regulating synapticvesicle fusion. Nature 388, 593-598, 1997.

Wang Y., Takeuchi T., Yokota H., and Izumi T.: Novel rabphilin3a protein associates with insulin-containing granules in pancreatic beta cells. J. Biol. Chem. 274, 2854228548, 1996.

Weber E., Jilling T., and Kirk K.L.: Distinct functional properties of Rab3A and Rab3B in PC12 neuroendrocrine cells. J. Biol. Chem. 271, 6963-6971, 1996.

Ybe J.A., Wakeham D.E., Brodsky F.M., and Hwang P.K.: Molecular structures of proteins involved in vesicle fusion. Traffic 1, 474-479, 2000

Yoshie S., Imai A., Nashida T., and Shimomura H.: Expression, characterization, and localization of Rab26, a low molecular weight GTP-binding protein, in the rat parotid gland. Histochem. Cell Biol. 113, 259-263, 2000.

Zerial M., and McBride H.: Rab proteins as membrane organizers. Nat. Rev. Mol. Cell Biol. 2, 107-117, 2001.

Zheng J.Y., Koda T., Fujiwara T., Kishi M., Ikehara Y., and Kakinuma M.: A novel Rab GTPase, Rab33B, is ubiquitously expressed and localized to the medial Golgi cisternae. J. Cell Sci. 111, 1061-1069, 1998

Zini N., Ognibene A., Bavelloni A., Santi S., Sabatelli P., Baldini N., Scotlandi K., Serra M., and Maraldi N.: Cytoplasmic and nuclear localization sites of phosphatidylinositol 3-kinase in human osteosarcoma sensitive and multidrug-resistant Saos-2 cells. Histochem. Cell Biol. 106, 457-464, 1996. 